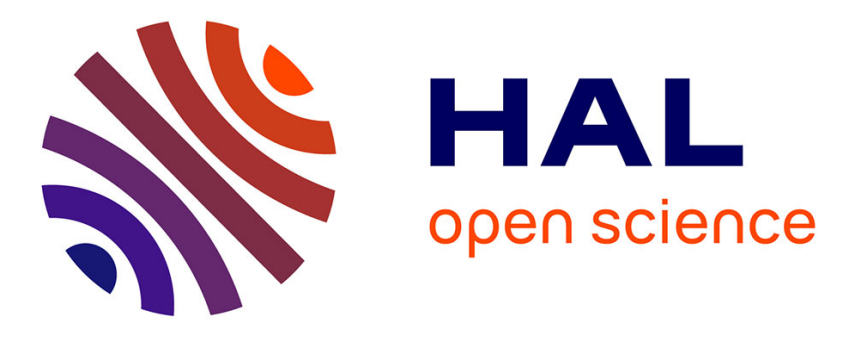

\title{
Pancreatic head cancer in patients with chronic pancreatitis
}

Aude Merdrignac, Laurent Sulpice, Michel Rayar, Tanguy Rohou, Emmanuel Quehen, Karim Boudjema, B. Meunier

\section{- To cite this version:}

Aude Merdrignac, Laurent Sulpice, Michel Rayar, Tanguy Rohou, Emmanuel Quehen, et al.. Pancreatic head cancer in patients with chronic pancreatitis. Hepatobiliary and Pancreatic Diseases International, 2014, 13 (2), pp.192-7. 10.1016/S1499-3872(14)60030-8 . hal-01069610

\section{HAL Id: hal-01069610 https://hal.science/hal-01069610}

Submitted on 8 Dec 2014

HAL is a multi-disciplinary open access archive for the deposit and dissemination of scientific research documents, whether they are published or not. The documents may come from teaching and research institutions in France or abroad, or from public or private research centers.
L'archive ouverte pluridisciplinaire HAL, est destinée au dépôt et à la diffusion de documents scientifiques de niveau recherche, publiés ou non, émanant des établissements d'enseignement et de recherche français ou étrangers, des laboratoires publics ou privés. 
Original article

Cancer of the pancreatic head occurring on chronic pancreatitis: a diagnosis forever inaccurate

Aude Merdrignac, M.D. ${ }^{1 \dagger}$, Laurent Sulpice, M.D.PhD ${ }^{1,3 \dagger}$, Michel Rayar, M.D. ${ }^{1}$, Tanguy Rohou, M.D.

${ }^{2}$, Emmanuel Quéhen, M.D. ${ }^{2}$, Karim Boudjema, M.D.PhD. ${ }^{1,3}$ and Bernard Meunier, M.D. ${ }^{1}$

Key words: Chronic pancreatitis, Adenocarcinoma, Pancreaticoduodenectomy.

Running title: Pancreatic adenocarcinoma on chronic pancreatitis. 


\begin{abstract}
Background: Chronic pancreatitis (CP) is a risk factor of pancreatic adenocarcinoma (PA). The discovery of a pancreatic head lesion in CP frequently leads to perform a pancreaticoduodenectomy (PD) which preceded by a Multidisciplinary Meeting (MM) discussion. The aim of this study was to evaluate the relevance between this indication of PD and the definitive pathological results.

Methods: Between 2000 and 2010, all patients with CP who underwent PD for suspicion of PA without any histological proof were retrospectively analyzed. The operative decision has always been taken in MM. The definitive pathological finding was retrospectively confronted with the MM's decision, and patients were classified in two groups according to this concordance (group 1) or not (group2). Clinical and biological parameters were analyzed, preoperative imaging were reread, and confronted to pathological findings in order to identify predictive factors of malignant degeneration.
\end{abstract}

Results: During the study period, 18 patients with CP had PD with 5 (27.7\%) patients who had PA histologically confirmed (group1) and $13(72.3 \%$ ) who had not (group2). The median age was 52.5 \pm 8.2 years (sex ratio 3.5$)$. The main symptoms were: pain $(94.4 \%)$ and weight loss $(72.2 \%)$. There was no postoperative mortality and morbidity was $61.1 \%(\mathrm{n}=11)$ with $27.7 \%(\mathrm{n}=5)$ of major complication (clavien-dindo classification $\geq 3$ ). . There was no statistical difference in clinical and biological parameters between the two groups. The rereading of imaging data could not detected efficiently all patients with PA.

Conclusions: Our results confirm the difficulty encountered to detect malignant transformation in patients with CP before the surgery and therefore an elevated rate of unnecessary PD was found. A uniform imaging protocol is necessary to avoid PD as a less invasive treatment could be proposed. 


\section{ABBREVIATIONS}

CP: chronic pancreatitis

CT: computed tomography

ERCP: endoscopic retrocholangiopancreatography

EUS: endoscopic ultrasound

FDG-PET: fluorodeoxyglucose positron emission tomography

MM: multidisciplinary meeting

MRCP: magnetic resonance cholangiopancreatography

PA: pancreatic adenocarcinoma

PD: pancreaticoduodenectomy

ROC: receiver operator curve

SD: standard derivation 


\section{INTRODUCTION}

Chronic pancreatitis (CP) is a risk factor of pancreatic adenocarcinoma (PA), with a 5 and 10 years cumulative incidence in large cohort studies of $1.1 \%$ and $1.7 \%(1,2)$. The median 5-year survival rate after diagnosis of PA is 4-6\% (all stages combined) (3,4), and surgery remains the only potential curative treatment (5), as current gemcitabline-based adjuvant chemotherapy protocols enable recurrence-free survival, reaching at best $23.5 \%$ and $16.5 \%$ at 3 and 5 years respectively (6). The diagnosis of PA is relatively simple in pancreatic body or tail, but is still difficult within a hypertrophic calcified head remodeled by CP. Then, the diagnosis of PA is often made only by imaging findings without histological proof related to the difficulty of obtaining adequate biopsy tissue with endoscopic ultrasound (EUS) (7). Nevertheless, the prognosis of malignant degeneration is so poor that PD is mandatory.

The difficulty of this situation is to balance the risk of misdiagnosing a malignant transformation and the high morbidity (30-70\%) associated with PD (8-10).

In our center, surgical indication is always discussed in Multidisciplinary Meeting (MM).

The main objective of this retrospective study was to analyze the degree of concordance between indications of PD for PA in CP without histological proof and the definitive pathological finding. Secondary objectives were to identify preoperative clinical and biological factors that could be predictive of malignant degeneration, and to evaluate radiological expertise in this situation. 


\section{PATIENTS AND METHODS}

\section{Patients}

After approval by our institutional review board, all data of patients who underwent PD from January 2000 to December 2010 in our tertiary center of pancreatic surgery have been collected and retrospectively analyzed.

Inclusion criteria were the presence of both $\mathrm{CP}$ and a focal head pancreatic lesion (either at diagnosis of CP or during follow-up), suspected to be a PA without histological proof (e.g EUS biopsies unrealizable or non-contributive). All indications of PD were established by MM with the participation of gastroenterologists, gastrointestinal surgeons and radiologists who reinterpreted patient's imaging. The main criterion for decision process was based on imaging findings (contrast enhancement, presence of bulky lymph nodes and aspect of retroportal lamina). Thereby, patients diagnosed as PA based on preoperative histology were excluded.

The clinical and biological data collected preoperatively were: age, gender, smoking habits, alcohol intake, symptoms, duration between the diagnosis of $\mathrm{CP}$ and the suspicion of PA, and blood work up results (aminotransferases, total and conjugated bilirubin, alkaline phosphatases, C-reactive protein).

The preoperative imaging available was: endoscopic retrograde cholangiopancreatography (ERCP); upper gastrointestinal EUS; computed tomography (CT); magnetic resonance cholangiopancreatography (MRCP). FDG-PET scan was not used routinely in our center.

The postoperative data analyzed were: length of hospital stay, morbidity, mortality and pathological findings.

\section{Definitions}

Postoperative mortality was defined as death during the hospital stay or within 30 days after surgery. Postoperative morbidity was defined according to the Clavien-Dindo classification (11). Postoperative complications included: pancreatic fistula classified into three groups according to the International Study Group of Pancreatic Fistula (ISGPF) criteria (12), delayed gastric emptying 
(DGE) classified according to the International Study Group of Pancreatic Surgery (ISGPS) criteria

(13) but only with grade B and C retained for this study, as our center policy was to maintain the nasogastric tube until at least postoperative day-5, postpancreatectomy hemorrhage including intraand extra luminal bleeding classified according to the ISGPS definition (14), and biliary fistula defined by biliary leakage in drains.

\section{Endpoints}

The main objective of our study was to analyze the degree of concordance between indications of PD for PA in CP without histological proof and the definitive pathological findings.

Secondary objectives were to identify preoperative clinical and biological factors that could be predictive of malignant degeneration, and to evaluate radiological expertise in this situation.

\section{Methods}

The impact of the radiological expertise was measured by a secondary analysis of available imaging documents (presence or absence of PA) performed by 2 senior radiologists both specialized in abdominal imaging. The two radiologists were both blinded to the pathological data and the previous radiological reports. Expert status has been defined as an experience in abdominal imaging over 5 years. The preoperative imaging documents reviewed were CT, MRCP and ERCP. The radiologists paid a particular attention to pancreatic trophicity (head, body and tail), characteristics of main pancreatic and biliary ducts (size, regularity), characteristics of pancreatic head nodules (localization, size, aspect), aspect of retroportal lamina, presence of pancreatic calcifications and peripancreatic infiltration, pseudocyst or lymph nodes.

Patients were divided into two groups according to pathological findings: group $1=\mathrm{CP}+\mathrm{PA}$; group $2=\mathrm{CP}$ alone. Univariate analysis was used to identify clinical and biological factors which are predictive of PA.

\section{Statistical analysis}


Quantitative data were expressed as median $(\mathrm{m}) \pm$ standard deviation $(\mathrm{SD})$ and compared with Student's $t$ test or the Mann-Whitney test as appropriate. Qualitative data were expressed as numbers and percentages in each group of patients and compared with Fisher's exact test. When a significant difference was found between the two groups, a receiver operator curve (ROC) was plotted to identify a threshold value.

A p value $<0.05$ was considered statistically significant. Statistical analysis was carried out by MATLAB version 7.11 (MathWorks Inc. Natick, Massachussets). 


\section{RESULTS}

A total of 314 patients underwent PD during the study period, including 18 (7.5\%) patients with suspected PA on $\mathrm{CP}$ without preoperative histological confirmation.

\section{Clinical, biological and imaging findings}

The median age was $52.5 \pm 8.2$ years. The sex ratio was 3.5 . The median duration of follow-up for $\mathrm{CP}$ before suspicion of PA was 9.5 months. The underlying cause of $\mathrm{CP}$ was alcohol $(\mathrm{n}=12,66.6 \%)$, cryptogenic $(n=4,22.2 \%)$ and genetic disease $(n=2,11.1 \%)$.

The clinical signs were pain $(n=17,94.4 \%)$, weight loss $(n=13,72.2 \%)$, jaundice $(n=8,44.4 \%)$, asthenia $(n=3,16.6 \%)$, and glycemic disorder $(n=1,5.55 \%)$ (Table1). Median levels of preoperative tumor biomarkers were 2.9 (range 1.7-6.9) and 13 (range 3-2056) for CEA and CA19.9, respectively. As these data were only available for 10 patients of the study population, we could not test them in the statistical analysis.

The preoperative imaging analyzed were abdominal CT for 16 patients (88.8\%), upper gastrointestinal EUS for 12 (66.6\%), MRCP for 7 (38.8\%) and ERCP for 5 (27.77\%).

The mean head nodule size (only available for 14 patients) was $1.8 \pm 0.4$ centimeters (range 1.22.5).

The EUS was particularly helpful in 10 cases: i) confirmed the presence of nodular lesions seen at CT scan or MRCP in 5 cases; ii) identified small nodular lesions in pancreatic head (not seen by CT scan or MRCP) in 4 cases; iii) found 1 lymph node not seen with CT-scan in 1 case.

The MRCP and ERCP were valuable in detecting main bile duct abnormalities. Indeed, ERCP identified: 2 irregularity and 3 strictures (complete in 1 case, and partial in 2 cases) of the main bile duct while MRCP identified 5 strictures (2 complete and 3 partial).

\section{Postoperative morbidity}

Postoperative complications are detailed in Table 2 and presented according to the Clavien classification in Table 3. There was no patient's death. The overall morbidity was $61.1 \%$ including $27.7 \%(\mathrm{n}=5)$ patients with a major complication (Clavien $\geq 3$ ). These complications required 
surgical reintervention for 4 patients $(22.22 \%)$ : 1 for hemorrhage, 1 for biliary, 1 for pancreatic fistula and 1 for both hemorrhage and biliary fistula. These 4 patients belonged to group 2 . Gastrojejunal anastomosis bleeding occurred in one another patient from group 2 who was treated endoscopically.

Pathology results

The histological examination confirmed the presence of PA in $5(27.7 \%)$ of the 18 patients.

\section{Predictive factors}

Univariate analysis revealed only one difference between the two groups: total bilirubin level was higher in group 1 (375 vs. $37 \mu \mathrm{mol} / \mathrm{l})$ without statistical significance $(\mathrm{p}=0.05)$ (Table 1$)$. The threshold determined from the ROC curve (Fig. 1) was $355 \mu \mathrm{mol} / 1$ which gave $75 \%$ sensibility and $100 \%$ specificity.

\section{Impact of the radiological expertise}

Only 14 patients (10 in group 1 and 4 in group 2) had available imaging for second radiological reading which could not detect all the patients with PA. The first radiologist concluded for presence of malignant lesions in $2(14.3 \%)$ patients who actually had PA, 10 (71.4\%) patients with benign lesions and could not conclude for $2(14.3 \%)$ patients. The second radiologist concluded for presence of malignant lesions in $5(35.7 \%)$ patients, including 3 who actually had PA, benign lesions in $7(50 \%)$ patients and could not conclude for $2(14.3 \%)$ patients. 


\section{DISCUSSION}

Chronic pancreatitis is an independent risk factor for pancreatic adenocarcinoma. The cumulative risk of PA is $1.8 \%$ and $4 \%$ at 10 and 20 years respectively (15). To date, no guidelines have yet been published regarding the imaging follow-up $(16,17)$, nevertheless this turning point in the evolution of $\mathrm{CP}$ justified to establish a radiological monitoring. The diagnosis of head localized PA is a serious challenge in patients with CP. This difficult situation represents $5.7 \%$ of the whole PD performed during the study period.

Our analysis showed that most of these decisions were incorrect. Indeed, the pathological examinations of the surgical specimens revealed that $72.3 \%$ of these patients were PA free whereas it reach 5-9\% without underlying CP $(18,19)$. These inappropriate decisions had major consequences since the postoperative morbidity was $61.1 \%$ (including $27.7 \%$ Clavien $\geq 3$ ) for these patients. Similar rates have been previously reported (20).

This hard decision-making process is hampered by the lack of informative clinical and biological data, as there are no specific signs differentiating PA and CP progression. In fact, our results showed no significant difference between our two groups in terms of clinical presentation as previously described $(18,21)$. However, our results revealed higher levels of total bilirubin in the patients from group 2 at the limit of statistical significance $(\mathrm{p}=0.05)$.

In addition, there is no consensus on tumor markers assay $(22,23)$. CA 19-9 would be the most sensitive marker but it can be valueless in context of cholestasis (24). To improve sensibility, some studies have proposed to associate K-ras gene mutation searching in the circulating DNA. The presence of this mutation, combined with an elevated CA19-9, would be associated with $95 \%$ sensibility $(25,26)$.

However, in clinical practice, radiological and EUS findings provides the key to diagnosis. For healthy pancreas, abdominal CT scan with IV contrast is the gold standard examination, both for diagnosis and disease spread (27). EUS is more sensitive, especially for small sized tumors, and also allows biopsy taking (28). However, in the context of CP, the sensibility of EUS is only 54- 
$74 \%(29,30)$. Nowadays, new EUS techniques associating enhanced contrast or elastography showed promising results but still need prospective studies to be validated $(31,32)$.

Because of the presence of parenchymatous calcifications and pancreatic head hypertrophy in $\mathrm{CP}$, imaging interpretation is limited (33). In order to improve the sensibility of radiological explorations, specific magnetic resonance sequences (T1-weighted echo-gradient with gadolinium injection, T2-weighted turbo-spin echo) have been developed (34). Similarly, the response to secretin has been used to highlight diminished exocrine function due to apparently tumor-related stricture of the main pancreatic canal $(35,36)$. Recently, diffusion magnetic resonance imaging has been tested in this indication and has shown significantly lower coefficients of diffusion in patients with PA (37). Small series have shown the potential usefulness of fluorodeoxyglucose positron emission tomography (FDG-PET) in this context with $83-86 \%$ sensibility $(38,39)$.

Finally, due to the lack of imaging explorations specificity, Gerstenmaeir et al. proposed an evidence-based decision-making algorithm applying the statistical probabilities of pre- and postexam malignancy described in the literature (40). The algorithm starts with an abdominal CT followed by an MRCP if positive. No further exploration is necessary if both the CT and the MRCP are negative; a follow-up with a regular abdominal CT can be proposed. In case of positive MRCP, EUS is performed, followed by FDG-PET if it is negative.

In our study, the rereading of images could not detect all the patients with PA although the radiologists had more time for interpretation and were free from the pressure of the MM. Nevertheless, the main limitation is that our study period is extended (10 years) and that all the different types of imaging were not available for all patients (explaining the lack of uniformly imaging protocol). The heterogeneity of the imaging protocols could explain the high number of false positive. Today, we perform in addition of systematic biomarkers assays (CA19.9 and CEA), the systematic realization of FDG-PET, diffusion MRI in order to improve the decision of MM.

We expected to find a successful attitude that will limit the number of unnecessary PD, and eventually propose to these symptomatic patients an appropriate endoscopic or other surgical 
treatment (i.e. Frey or Beger procedure) which are associated with lower morbidity (10-30\% and $20-40 \%$ for the Frey and Beger procedure, respectively) $(41,42)$ and improved long-term quality of life (43).

In summary, our results were in line with the literature and confirmed the difficulty encountered to establish an accurate diagnosis of PA in CP. Consequently, the doubt about diagnosis leads to an over-indication of PD during the MM. This study confirms the necessity of a uniform validated imaging protocol to improve the decision making process in MM. 


\section{REFERENCES}

1. Malka D, Hammel P, Maire F, Rufat P, Madeira I, Pessione F, et al. Risk of pancreatic adenocarcinoma in chronic pancreatitis. Gut. 2002. 51(6):849. PMID:12427788.

2. Karlson BM, Ekbom A, Josefsson S, McLaughlin JK, Fraumeni JF Jr, Nyrén O. The risk of pancreatic cancer following pancreatitis: an association due to confounding? Gastroenterology. 1997; 113(2):587-592. PMID: 9247480.

3. Cleary SP, Gryfe R, Guindi M, Greig P, Smith L, Mackenzie R, et al. Prognostic factors in resected pancreatic adenocarcinoma: analysis of actual 5-year survivors. J Am Coll Surg. 2004; 198(5):722-731. PMID:15110805.

4. Jemal A, Siegel R, Xu J, Ward E. Cancer statistics, 2010. CA Cancer J Clin. 2010; 60(5):277-300. PMID:20610543.

5. Vincent A, Herman J, Schulick R, Hruban RH, Goggins M. Pancreatic cancer. Lancet. 2011; 378(9791):607-620. PMID:21620466.

6. Oettle H, Post S, Neuhaus P, Gellert K, Langrehr J, Ridwelski K, et al. Adjuvant chemotherapy with gemcitabine vs observation in patients undergoing curative-intent resection of pancreatic cancer: a randomized controlled trial. JAMA. 2007; 297(3):267-277. PMID:17227978.

7. Krishna NB, Mehra M, Reddy AV, Agarwal B. EUS/EUS-FNA for suspected pancreatic cancer: influence of chronic pancreatitis and clinical presentation with or without obstructive jaundice on performance characteristics. Gastrointest Endosc. 2009; 70(1):70-79. PMID:19249774.

8. Huguier M, Mason NP. Treatment of cancer of the exocrine pancreas. Am J Surg. 1999; 177(3):257-265. PMID:10219866.

9. Schäfer M, Müllhaupt B, Clavien P-A. Evidence-based pancreatic head resection for pancreatic cancer and chronic pancreatitis. Ann Surg. 2002; 236(2):137-148. PMID:12170018.

10. Russell RCG, Theis BA. Pancreatoduodenectomy in the Treatment of Chronic Pancreatitis. World J Surg. 2003; 27(11):1203-1210. PMID:14534820. 
11. Dindo D, Demartines N, Clavien P-A. Classification of surgical complications: a new proposal with evaluation in a cohort of 6336 patients and results of a survey. Ann Surg. 2004; 240(2):205-213. PMID:15273542.

12. Bassi C, Dervenis C, Butturini G, Fingerhut A, Yeo C, Izbicki J, et al. Postoperative pancreatic fistula: an international study group (ISGPF) definition. Surgery. 2005; 138(1):8-13. PMID:16003309.

13. Wente MN, Bassi C, Dervenis C, Fingerhut A, Gouma DJ, Izbicki JR, et al. Delayed gastric emptying (DGE) after pancreatic surgery: a suggested definition by the International Study Group of Pancreatic Surgery (ISGPS). Surgery. 2007; 142(5):761-768. PMID:17981197.

14. Wente MN, Veit JA, Bassi C, Dervenis C, Fingerhut A, Gouma DJ, et al. Postpancreatectomy hemorrhage (PPH): an International Study Group of Pancreatic Surgery (ISGPS) definition. Surgery. 2007; 142(1):20-25. PMID:17629996.

15. Lowenfels AB, Maisonneuve P, Cavallini G, Ammann RW, Lankisch PG, Andersen JR, et al. Pancreatitis and the risk of pancreatic cancer. International Pancreatitis Study Group. N Engl J Med. 1993; 328(20):1433-1437. PMID:8479461.

16. Frulloni L, Falconi M, Gabbrielli A, Gaia E, Graziani R, Pezzilli R, et al. Italian consensus guidelines for chronic pancreatitis. Dig Liver Dis. 2010; 42, Supplement 6(0):S381-S406. PMID:21078490.

17. Raimondi S, Lowenfels AB, Morselli-Labate AM, Maisonneuve P, Pezzilli R. Pancreatic cancer in chronic pancreatitis; aetiology, incidence, and early detection. Best Pract Res Clin Gastroenterol. 2010; 24(3):349-358. PMID:20510834.

18. Van Gulik TM, Reeders JW, Bosma A, Moojen TM, Smits NJ, Allema JH, et al. Incidence and clinical findings of benign, inflammatory disease in patients resected for presumed pancreatic head cancer. Gastrointest Endosc. 1997; 46(5):417-423. PMID:9402115. 
19. De Castro SMM, De Nes LCF, Nio CY, Velseboer DC, Kate FJWT, Busch ORC, et al. Incidence and characteristics of chronic and lymphoplasmacytic sclerosing pancreatitis in patients scheduled to undergo a pancreatoduodenectomy. HPB. 2009; 12(1):15-21. PMID:20495640.

20. Enestvedt CK, Diggs BS, Cassera MA, Hammill C, Hansen PD, Wolf RF. Complications nearly double the cost of care after pancreaticoduodenectomy. Am J Surg. Epub 2012. PMID:22464011.

21. Evans JD, Morton DG, Neoptolemos JP. Chronic pancreatitis and pancreatic carcinoma. Postgrad Med J. 1997; 73(863):543-548. PMID:9373592.

22. Goggins M. Identifying Molecular Markers for the Early Detection of Pancreatic Neoplasia. Semin Oncol. 2007; 34(4):303-310. PMID:17674958.

23. Duffy MJ, Sturgeon C, Lamerz R, Haglund C, Holubec VL, Klapdor R, et al. Tumor markers in pancreatic cancer: a European Group on Tumor Markers (EGTM) status report. Ann Oncol. 2010; 21(3):441-447. PMID:19690057.

24. Singh S, Tang S, Sreenarasimhaiah J, Lara LF, Siddiqui A. The clinical utility and limitations of serum carbohydrate antigen (CA19-9) as a diagnostic tool for pancreatic cancer and cholangiocarcinoma. Dig Dis Sci.2011; 56(8):2491-2496. PMID:21516323.

25. Maire F, Micard S, Hammel P, Voitot H, Lévy P, Cugnenc P-H, et al. Differential diagnosis between chronic pancreatitis and pancreatic cancer: value of the detection of KRAS2 mutations in circulating DNA. Br J Cancer. 2002; 87(5):551-554. PMID:12189555.

26. Theodor L, Melzer E, Sologov M, Idelman G, Friedman E, Bar-Meir S. Detection of pancreatic carcinoma: diagnostic value of K-ras mutations in circulating DNA from serum. Dig. Dis. Sci. 1999; 44(10):2014-2019. PMID:10548352.

27. McNulty NJ, Francis IR, Platt JF, Cohan RH, Korobkin M, Gebremariam A. Multi-Detector Row Helical CT of the Pancreas: Effect of Contrast-enhanced Multiphasic Imaging on 
Enhancement of the Pancreas, Peripancreatic Vasculature, and Pancreatic Adenocarcinoma1. Radiology. 2001; 220(1):97-102. PMID:11425979.

28. Tamm EP, Loyer EM, Faria SC, Evans DB, Wolff RA, Charnsangavej C. Retrospective analysis of dual-phase MDCT and follow-up EUS/EUS-FNA in the diagnosis of pancreatic cancer. Abdom Imaging. 2007; 32(5):660-667. PMID:17712589.

29. Fritscher-Ravens A, Brand L, Knöfel WT, Bobrowski C, Topalidis T, Thonke F, et al. Comparison of endoscopic ultrasound-guided fine needle aspiration for focal pancreatic lesions in patients with normal parenchyma and chronic pancreatitis. Am J Gastroenterol. 2002; 97(11):2768-2775. PMID:12425546.

30. Varadarajulu S, Tamhane A, Eloubeidi MA. Yield of EUS-guided FNA of pancreatic masses in the presence or the absence of chronic pancreatitis. Gastrointest. Endosc. 2005; 62(5):728-736; quiz 751, 753. PMID:16246688.

31. Gheonea DI, Streba CT, Ciurea T, Săftoiu A. Quantitative low mechanical index contrastenhanced endoscopic ultrasound for the differential diagnosis of chronic pseudotumoral pancreatitis and pancreatic cancer. BMC Gastroenterol. 2013 Jan 3;13:2. PMID: 23286918.

32. Săftoiu A, Iordache SA, Gheonea DI, Popescu C, Maloş A, Gorunescu F, Ciurea T, Iordache A, Popescu GL, Manea CT. Combined contrast-enhanced power Doppler and real-time sonoelastography performed during EUS, used in the differential diagnosis of focal pancreatic masses (with videos). Gastrointest Endosc. 2010 Oct;72(4):739-47. doi: 10.1016/j.gie.2010.02.056. Epub 2010 Aug 2. PMID: 20674916.

33. Oto A, Eltorky MA, Dave A, Ernst RD, Chen K, Rampy B, et al. Mimicks of pancreatic malignancy in patients with chronic pancreatitis: correlation of computed tomography imaging features with histopathologic findings. Curr Probl Diagn Radiol. 2006; 35(5):199-205. PMID:16949476. 
34. Kim JK, Altun E, Elias J Jr, Pamuklar E, Rivero H, Semelka RC. Focal pancreatic mass: distinction of pancreatic cancer from chronic pancreatitis using gadolinium-enhanced 3D-gradientecho MRI. J Magn Reson Imaging. 2007; 26(2):313-322. PMID:17610286.

35. Matos C, Bali MA, Delhaye M, Devière J. Magnetic resonance imaging in the detection of pancreatitis and pancreatic neoplasms. Best Pract Res Clin Gastroenterol. 2006; 20(1):157-178. PMID:16473806.

36. Klau M, Lemke A, Grünberg K, Simon D, Re TJ, Wente MN, et al. Intravoxel Incoherent Motion MRI for the Differentiation Between Mass Forming Chronic Pancreatitis and Pancreatic Carcinoma. Invest Radiol. 2011; 46(1):57-63. PMID:21139505.

37. Fattahi R, Balci NC, Perman WH, Hsueh EC, Alkaade S, Havlioglu N, et al. Pancreatic diffusion-weighted imaging (DWI): comparison between mass-forming focal pancreatitis (FP), pancreatic cancer (PC), and normal pancreas. J Magn Reson Imaging. 2009; 29(2):350-356. PMID:19161187.

38. Van Kouwen MCA, Jansen JBMJ, Van Goor H, De Castro S, Oyen WJG, Drenth JPH. FDG-PET is able to detect pancreatic carcinoma in chronic pancreatitis. Eur $\mathrm{J}$ Nucl Med Mol Imaging. 2005; 32(4):399-404. PMID:15549297.

39. Singer E, Gschwantler M, Plattner D, Kriwanek S, Armbruster C, Schueller J, et al. Differential diagnosis of benign and malign pancreatic masses with 18F-fluordeoxyglucose-positron emission tomography recorded with a dual-head coincidence gamma camera. Eur J Gastroenterol Hepatol. 2007; 19(6):471 -478. PMID:17489057.

40. Gerstenmaier JF, Malone DE. Mass lesions in chronic pancreatitis: benign or malignant? An « evidence-based practice » approach. Abdom Imaging. 2011; 36(5):569-577. PMID:21046100.

41. Izbicki JR, Bloechle C, Knoefel WT, Kuechler T, Binmoeller KF, Broelsch CE. Duodenumpreserving resection of the head of the pancreas in chronic pancreatitis. A prospective, randomized trial. Ann Surg. 1995; 221(4):350-358. PMID:7726670. 
42. Keck T, Wellner UF, Riediger H, Adam U, Sick O, Hopt UT, et al. Long-term outcome after 92 duodenum-preserving pancreatic head resections for chronic pancreatitis: comparison of Beger and Frey procedures. J Gastrointest Surg. 2010; 14(3):549-556. PMID:20033344.

43. Regimbeau J-M, Dumont F, Yzet T, Chatelain D, Bartoli ER, Brazier F, et al. Surgical management of chronic pancreatitis. Gastroenterol Clin Biol. 2007; 31(8-9 Pt 1):672-685. PMID:17925767. 


\begin{tabular}{|c|c|c|c|c|c|}
\hline & & All patients & Group 1 & Group 2 & $\mathrm{p}$ \\
\hline Number of & patients & 18 & $5(27.8 \%)$ & $13(72.2 \%)$ & \\
\hline Age (years) & & $52.5+/-8.2$ & $55+/-4.3$ & $51+/-9.3$ & 0.45 \\
\hline Gender & Male & $14(77.7 \%)$ & $5(100 \%)$ & $9(69.2 \%)$ & 0.27 \\
\hline & Female & $4(22.2 \%)$ & 0 & $4(30.8 \%)$ & \\
\hline Symptoms & Pain & $17(94.4 \%)$ & $4(80 \%)$ & $13(100 \%)$ & 0.27 \\
\hline & Weight loss & $13(72.2 \%)$ & $4(80 \%)$ & $9(69.2 \%)$ & 1 \\
\hline & Jaundice & $8(44.4 \%)$ & $3(60 \%)$ & $5(38.5 \%)$ & 0.60 \\
\hline & Asthenia & $3(16.6 \%)$ & $2(40 \%)$ & $1(7.7 \%)$ & 0.17 \\
\hline & Loss of glycemic control & $1(5.5 \%)$ & $1(20 \%)$ & 0 & 0.27 \\
\hline Weight loss & (\% of body mass) & 5.19 & 6.94 & 4.58 & 0.29 \\
\hline Smoking & & $16(88.8 \%)$ & $4(80 \%)$ & $12(92.3 \%)$ & 0.49 \\
\hline Alcohol int: & & $13(72.2 \%)$ & $2(40 \%)$ & $11(84.6 \%)$ & 0.09 \\
\hline $\begin{array}{l}\text { Time from } \\
\text { (months) }\end{array}$ & liagnosis of $\mathrm{CP}$ and surgery & 9.5 & 3 & 12 & 1 \\
\hline Blood tests & ASAT (UI/l) & 50 & 77 & 47.5 & 0.62 \\
\hline & ALAT (UI/l) & 83 & 106 & 76.5 & 0.59 \\
\hline & GGT (UI/l) & 329.5 & 382 & 324 & 0.51 \\
\hline & Alkaline phosphatases (UI/l) & 539 & 1510 & 525 & 0.23 \\
\hline & Total bilirubin $(\mu \mathrm{mol} / \mathrm{l})$ & 43 & 375 & 37 & 0.05 \\
\hline & Conjugated bilirubin $(\mu \mathrm{mol} / \mathrm{l})$ & 18 & 214.5 & 15 & 0.18 \\
\hline & C-reactive protein (mg/l) & 5 & 6 & 5 & 0.79 \\
\hline
\end{tabular}

Table 1: Preoperative clinical and biological data in the two groups of patients expressed as number, percentage and median $+/-\mathrm{SD}$ (group $1=\mathrm{CP}+\mathrm{PA}$, group $2=\mathrm{CP}$ ); significance: $\mathrm{p}<0.05$. 


\begin{tabular}{lccc} 
& All patients & Group 1 & Group 2 \\
\hline Delayed gastric emptying (at least grade B) & 5 & 1 & 4 \\
Lymphorrhea & 3 & 2 & 1 \\
Ascitis & 1 & 0 & 1 \\
Transfusion & 7 & 1 & 1 \\
Wall abscess & 2 & 0 & 1 \\
Respiratory failure & 1 & 1 & 0 \\
Functional obstruction & 1 & 0 & 3 \\
Hemorrhage & 3 & 0 & 1 \\
Pancreatic fistula & 1 & 0 & 3 \\
Biliary fistula & 3 & 0 & 4 \\
Revision surgery & 4 & 0 & 0 \\
Death & 0 & $20.8+/-12.4$ & $20+/-17.4$ \\
Length of hospital stay (days) & $20.2+/-15.8$ & & \\
\hline
\end{tabular}

Table 2: Postoperative complications and duration of hospital stay (median $\pm \mathrm{SD}$ ). 


\begin{tabular}{cccc}
$\begin{array}{c}\text { Grade of Clavien-Dindo } \\
\text { classification }\end{array}$ & All patients & Group 1 & Group 2 \\
\hline 1 & 2 & 1 & 0 \\
2 & 4 & 1 & 3 \\
3 & 2 & 1 & 1 \\
4 & 3 & 0 & 3 \\
5 & 0 & 0 & 0 \\
\hline Total & $11(61.1 \%)$ & 3 & 9 \\
\hline
\end{tabular}

Table 3: Distribution of complications in the two groups according to the Clavien-Dindo classification. 


\section{LEGEND}

Figure 1: ROC of the total bilirubin rate for diagnosis of PA. 


\section{FIGURE}

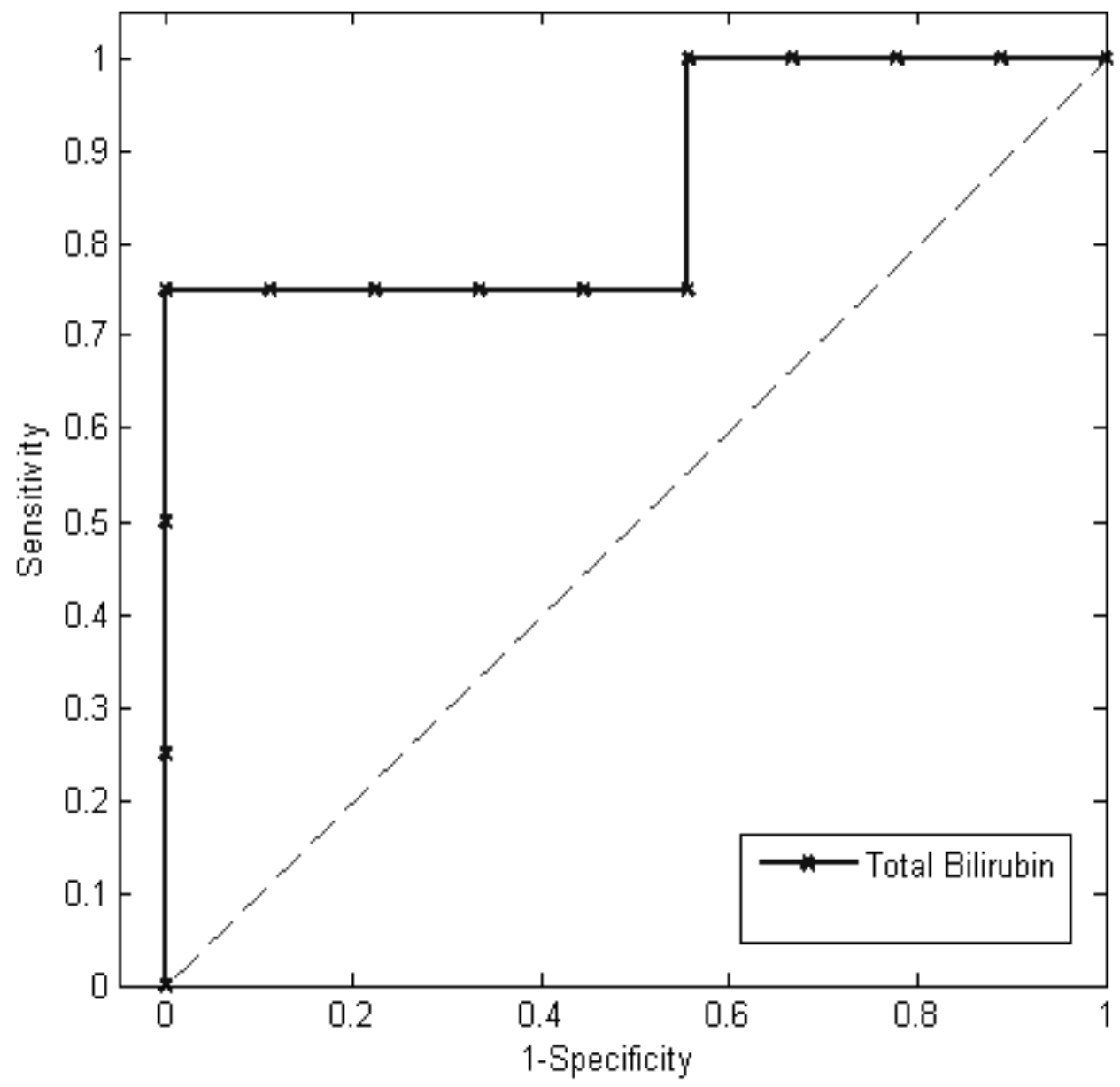

Figure 1 